\begin{tabular}{|c|l|}
\hline Title & Reaction characteristics of combustion synthesis of $\beta$-SiA ION using different additives \\
\hline Author(s) & Niu, Jing; Nakamura, Tomokazu; Nakatsugawa, Isao; A kiyama, Tomohiro \\
\hline Citation & $\begin{array}{l}\text { Chemical Engineering Journal, 241, 235-242 } \\
\text { https://doi.org/10.1016/.cej.2013.12.030 }\end{array}$ \\
\hline Issue Date & 2014.04.01 \\
\hline Doc URL & http://hdl.handle.net/2115/57630 \\
\hline Type & article (author version) \\
\hline File Information & revised manuscript-2.pdf \\
\hline
\end{tabular}

Instructions for use 


\title{
Reaction characteristics of combustion synthesis of $\beta$-SiAION using different additives
}

\author{
Jing Niu ${ }^{1}$, Tomokazu Nakamura ${ }^{1}$ Isao Nakatsugawa ${ }^{2}$,Tomohiro Akiyama ${ }^{\text {l\# }}$ \\ ${ }^{1}$ Center for Advanced Research of Energy and Materials, Hokkaido University, Kita \\ 13 Nishi 8, Kitaku, Sapporo 060-8628, Japan \\ ${ }^{2}$ Combustion Synthesis Co., Ltd., Numazu, Shizuoka 410-0801, Japan
}

${ }^{\#}$ Corresponding author: Tel.: +81 11706 6842; Fax: +81 117260731

E-mail address: takiyama@eng.hokudai.ac.jp 


\begin{abstract}
Reaction characteristics of combustion synthesis $\left(\mathrm{CS}^{1}\right)$ of $\beta$-SiAlON powders in a horizontal CS chamber were compared by including two types of additives $(\beta-\mathrm{SiAlON}$ and $\mathrm{NaCl})$ in $\mathrm{Si}, \mathrm{SiO}_{2}$, and $\mathrm{Al}$ powder raw materials. The results showed that the reaction characteristics were influenced by the additives, which exerted a strong effect on the reaction rate and the morphology of the products. At the respective maximum combustion temperatures, a relatively slow conversion rate, with a reacted fraction $(\eta)$ of $58.7 \%$, was achieved with the addition of 12 mass $\% \mathrm{NaCl}$ to the raw materials, whereas the addition of 45 mass $\% \beta$-SiAlON powders afforded $\eta=$ $88 \%$. The $\mathrm{NaCl}$ additive yielded rod-like crystals, which were well developed by a long after-burn time. However, self-sintering occurred in the presence of $\beta$-SiAlON powders. The results indicate that some degree of control over the conversion rate of the reaction and the microstructures of the product can be achieved by varying the type of additives.
\end{abstract}

Keywords: Combustion synthesis; $\beta$-SiAlON; Reaction characteristics; Temperature profile; Microstructure

\footnotetext{
1 Abbreviations: Al/ $\beta$-SiAlON, Al and $\beta$-SiAlON; CS, combustion synthesis; D45, 45 mass\% $\beta$-SiAlON; $\eta$, reacted fraction; LED, light-emitting diode; $\mathrm{N} 12,12$ mass $\% \mathrm{NaCl} ; Q$, endothermic value; SEM, scanning electron microscopy; VLS, vapor-liquid-solid; XRD, X-ray diffraction.
} 


\section{Introduction}

$\beta$-SiAlONs, derived from the $\beta-\mathrm{Si}_{3} \mathrm{~N}_{4}$ structure by the equivalent substitution of $\mathrm{Si}-\mathrm{N}$ with $\mathrm{Al}-\mathrm{O}$, have the general formula $\mathrm{Si}_{6-z} \mathrm{Al}_{z} \mathrm{O}_{z} \mathrm{~N}_{8-z}(0<\mathrm{z} \leq 4.2)$. They are attractive materials for application in high-temperature engineering systems because of their high strength and hardness, good thermal and chemical stability, and superior wear and thermal shock resistance [1-3]. Recently, rare-earth-doped $\beta$-SiAlONs have been recognized as potential phosphors for application to white light-emitting diodes (LEDs) because of their intense photoluminescence and high thermal stability [4-6].

Low-cost production of $\beta$-SiAlON is crucial for achieving widespread applications. Their synthesis generally involves sintering of high-purity $\mathrm{Si}_{3} \mathrm{~N}_{4}, \mathrm{AlN}$, and $\mathrm{Al}_{2} \mathrm{O}_{3}$ at temperatures of $1700-2000{ }^{\circ} \mathrm{C}$ for many hours under nitrogen pressure $[7,8] . \mathrm{Si}_{3} \mathrm{~N}_{4}$ and $\mathrm{AlN}$ must be synthesized prior to the sintering process as an additional step. Consequently, the process is limited by many disadvantages such as the need for multistep processes that are energy- and time-consuming. The carbothermal reduction and nitridation $(\mathrm{CRN})[9,10]$ method using kaolin and a carbon mixture as raw materials is regarded as an economically attractive process for producing $\beta$-SiAlON. However, the practical application of this method has been limited thus far by the low purity of the products, as they usually contains a number of undesirable by-products, such as $\mathrm{SiC}$ and AlN.

Combustion synthesis (CS) is a recognized alternative to conventional methods of powders synthesis for producing various industrial materials [11-14], particularly ceramics [15-18]. This process exploits a self-sustaining regime that utilizes the heat generated during a strongly exothermic reaction. No external energy is required, except for the ignition energy. This method has many advantages, including low energy input, a short reaction time, simple equipment, and high-purity products. Most reported syntheses of $\beta$-SiAlON via CS required high $\mathrm{N}_{2}$ pressure $(2-150 \mathrm{MPa})$ to drive the reaction to completion [19]. However, $\beta$-SiAlONs have been successfully synthesized under a low nitrogen pressure of $1 \mathrm{MPa}$ as well [20-22]. Additionally, inexpensive $\mathrm{Si}, \mathrm{Al}$, and $\mathrm{SiO}_{2}$ powders have been used as raw materials. Nevertheless, 
the combustion temperatures are extremely high and $\mathrm{Si}$ particles melt in the combustion front and coalesce during reaction, which inhibits complete nitridation. To decrease reaction heat as well as to slow down the combustion temperature, a large amount of the $\beta$-SiAlON product (50 mass\%) must be added to the starting materials as a diluent [23-25], which, however, decreases the product yield. Moreover, using final product as diluents does not usually provide a product with submicron particles although the CS temperature decreases. Thus, to obtain a product with a fine grain size, the post-synthesis treatment is necessary.

Recently, $\mathrm{NaCl}$ has been used as a diluent in $\mathrm{CS}$ for the synthesis of some ceramics, such as $\mathrm{TiC}, \mathrm{ZrB}_{2}$, and $\mathrm{TiB}_{2}$ powders [26-28]. It was reported that the addition of $\mathrm{NaCl}$ lowers the $\mathrm{CS}$ temperature and results in a decrease in the particle size of the final products. In our previous work, single-phase $\beta$-SiAlON powders with submicron dimensions were successfully synthesized by addition of a small amount of $\mathrm{NaCl}$ [29]. $\mathrm{NaCl}$ acted as an efficient diluent that absorbed the reaction heat by converting it to the latent heat of phase transformation. However, execution of this new CS process under industrial conditions using a large sample size is still a challenge.

Herein, this novel synthesis process is extended to industrial conditions, in which the sample was positioned horizontally. In order to compare, the same experiment was carried out using the $\beta$-SiAlON product as a diluent. This is the first execution of this method using a horizontal-type chamber and employing low-cost $\mathrm{Si}, \mathrm{Al}$, and $\mathrm{SiO}_{2}$ as raw materials, along with the comparison of the characteristics of the reaction process and kinetic of the reaction on propagation using Boddington's model. 


\section{Experimental procedure}

Our previous work has merely been examined under laboratory conditions using a small amount of raw materials. Furthermore, the sample was longitudinally positioned and the top of the sample was ignited according to the classical CS process, which is not suitable for commercial processing. Therefore, in this work, to execute this new CS process under industrial conditions, the sample was positioned horizontally. Besides, amount of $\beta$-SiAlON powders were used to surround the sample, which can reduce the heat exchanges with the surroundings.

The starting materials used in this work were commercially available powders of Si (6 $\mu \mathrm{m}$, purity $>98 \%$, Kinseimatec Co., Ltd., Japan), Al (14 $\mu \mathrm{m}$, purity $>99.7 \%$, Minalco Co., Ltd., Japan), $\mathrm{SiO}_{2}(12 \mu \mathrm{m}$, purity $>99 \%$, Takeori. Co., Ltd., Japan), $\beta$-SiAlON (0.5 $\mu \mathrm{m}$, ISMAN J Corporation, Kawasaki, Japan), and $\mathrm{NaCl}$ (purity 99.9\%, Kojundo Chemical Laboratory Co., Ltd., Japan). The reaction characteristics of the combustion synthesis process were compared for the addition of either 45 mass $\%$ $\beta$-SiAlON (denoted D45) or 12 mass $\% \mathrm{NaCl}$ (denoted N12) to the starting materials. The reactions for the combustion synthesis of $\beta-\mathrm{Si}_{5} \mathrm{AlON}_{7}\left(\beta-\mathrm{Si}_{6-\mathrm{z}} \mathrm{Al}_{\mathrm{z}} \mathrm{O}_{\mathrm{z}} \mathrm{N}_{8-\mathrm{z}}, \mathrm{z}=1\right)$ using $\beta$-SiAlON and $\mathrm{NaCl}$ as the diluent can be described by the following equations:

$$
\begin{aligned}
& 4.5 \mathrm{Si}+\mathrm{Al}+0.5 \mathrm{SiO}_{2}+3.5 \mathrm{~N}_{2}+0.427 \mathrm{NaCl} \rightarrow \beta-\mathrm{Si}_{5} \mathrm{AlON}_{7}+0.427 \mathrm{NaCl} \\
& 4.5 \mathrm{Si}+\mathrm{Al}+0.5 \mathrm{SiO}_{2}+3.5 \mathrm{~N}_{2}+0.533 \mathrm{Si}_{5} \mathrm{AlON}_{7} \rightarrow 1.533 \beta-\mathrm{Si}_{5} \mathrm{AlON}_{7}
\end{aligned}
$$

All reactants were weighed according to the stoichiometric ratio. The reactant powders were mechanically activated by planetary ball-milling at a ball-to-sample mass ratio of 10:1 for $15 \mathrm{~min}$. Then, $120 \mathrm{~g}$ of the activated mixture was loosely packed into a graphite crucible with dimensions $80 \times 130 \times 45 \mathrm{~mm}$. The experimental setup is shown in Fig. 1. Two W-Re type thermocouples protected by alumina sheaths were inserted into the center of the sample to record the combustion temperature profiles. The propagation velocity of the combustion front was determined by measuring the time that lapsed between the two thermocouples, which were embedded at a distance of $40 \mathrm{~mm}$. Nitrogen (purity: 99.999\%) was charged into the 
chamber up to a pressure of $1 \mathrm{MPa}$. To minimize the oxygen concentration in the chamber, the vacuuming/pressurizing with nitrogen was repeated twice. Combustion was triggered by igniting the $\mathrm{Al}$ and $\beta-\mathrm{SiAlON}(\mathrm{Al} / \beta-\mathrm{SiAlON}=50 / 50$ mass $\%$ ) powders by passing an electric current though the carbon foil placed on one end of the sample.

The experimental procedures employing both types of additives are compared in Fig. 2. As shown in this figure, when using 45 mass $\% \beta$-SiAlON product as diluents, the as-synthesized $\beta$-SiAlON product generated by addition of commercial $\beta$-SiAlON powder (ISMAN J, $0.5 \mu \mathrm{m}$ ) as the diluent was crushed in a mortar and then sieved through a 220-mesh sieve and milled to approximately $5 \mu \mathrm{m}$ to be used as the diluent for the second combustion reaction under the same conditions. This process was repeated for several times. It is obvious that this approach has a drawback of having multistep pathways and a low product yield. Furthermore, the products were extremely hard and difficult to mill into powders. However, using 12 mass $\% \mathrm{NaCl}$ as the diluent has the merit of high-efficiency and energy-saving process. In addition, the product obtained by addition of $\mathrm{NaCl}$ was readily pulverized by crushing.

The phase compositions of the combustion-synthesized products were analyzed via X-ray diffraction (XRD, $\mathrm{Cu} \mathrm{K \alpha}$, Rigaku, Japan), the accelerating voltage and current are $30 \mathrm{kV}$ and $15 \mathrm{~mA}$, respectively, and the scanning angle of the detector was varied within the range $10-60^{\circ}(2 \theta)$ with a step of $0.02^{\circ}$ and fixed counting time of $0.5 \mathrm{~s}$. The lattice parameters of the hexagonal $\beta$-SiAlON were calculated from the XRD peaks (100), (110), (200), (101), (210), (201), (301), (320), (321), and (411) using pure Si as an internal standard. The microstructures were observed via scanning electron microscopy (FE-SEM, JSM-7400F, JEOL, Japan). The data for calculating the heat change caused by $\mathrm{NaCl}$ was taken from the database of the HSC Chemistry software Ver. 5.11. 


\section{Results and discussion}

\subsection{Characterization of the raw materials}

The morphology of the raw materials before CS of $\beta-\mathrm{SiAlON}$ is presented in Fig. 3. When using 45 mass $\% \beta$-SiAlON powders as diluents, Si grains are covered by some small ones, which are agglomerated together. In contrast, the raw materials exhibit well-distributed particles when using 12 mass $\% \mathrm{NaCl}$ as diluents. The result indicates $\mathrm{NaCl}$ prevented the agglomeration of the raw materials during the milling. To obtain a precise estimation of the particle-size distribution for the two kinds of raw materials, particle-size distribution measurement was performed by laser particle-size analyzer. The results are given in Fig. 4. D45 was composed of particles with a median diameter of $\sim 4.2 \mu \mathrm{m}$, which are smaller than that of N12 with a median diameter of $\sim 6 \mu \mathrm{m}$. The differences are attributed to the addition of amount of small sized $\beta$-SiAlON diluents in D45.

\subsection{Change in enthalpy of the raw materials}

Fig. 5 shows the heat contents of $\beta$-SiAlON and $\mathrm{NaCl}$ during the $\mathrm{CS}$ processes, which were calculated using the data acquired from a laser-flash method and taken from the database of HSC Chemistry software Ver.5.11, respectively. The endothermic value $(Q, \mathrm{~kJ} / \mathrm{kg})$ of $\beta$-SiAlON was estimated using the following equation:

$$
\mathrm{Q}_{\beta-\mathrm{SiAlON}}=\int_{T_{0}}^{T} C p(T) d T
$$

where $C p(T)$ is the specific heat capacity of $\beta$-SiAlON $(z=1)$ in $\mathrm{kJ} /(\mathrm{kg} \cdot \mathrm{K})$, and $Q$ in $\mathrm{kJ} / \mathrm{kg}, C p=0.731 \mathrm{~kJ} /(\mathrm{kg} \cdot \mathrm{K})$ was the measured value from the laser-flash method. The endothermic value of $\mathrm{NaCl}$ was calculated using the specific heat and latent heat of its melting and evaporation, which could be determined from the following formula:

$\mathrm{Q}_{\mathrm{NaCl}}=\int_{T_{0}}^{T_{m}} C p(T) d T+Q_{s l}+\int_{T_{m}}^{T_{b}} C p(T) d t+Q_{l g}+\int_{T_{b}}^{T} C p(T) d t$

and $C p$ was $0.861 \mathrm{~kJ} /(\mathrm{kg} \cdot \mathrm{K})$, the data used in this calculation were taken from 
software HSC chemistry Ver.5.11. The values of specific heat capacity and heat capacity formula of $\beta-\mathrm{SiAlON}$ and $\mathrm{NaCl}$ can be found in Table 1 . It is evident that the endothermic value of $\mathrm{NaCl}(1403 \mathrm{~kJ} / \mathrm{kg}$ at $1073 \mathrm{~K})$ was larger than that of $\beta$-SiAlON $(938 \mathrm{~kJ} / \mathrm{kg}$ at $1073 \mathrm{~K})$ at temperatures of equal and higher than the $\mathrm{NaCl}$ melting point because of the high latent heat of phase transformation of $\mathrm{NaCl}$.

Based on our previous studies [29,30], two endothermic processes can be defined with the addition of these additives, corresponding to a two-stage exothermic process for the CS of $\beta$-SiAlON. The first stage exothermic process involving the reaction of $\mathrm{Al}$ and $\mathrm{N}_{2}$ to form $\mathrm{AlN}$ and $\mathrm{Al}$ and $\mathrm{SiO}_{2}$ to form $\mathrm{Al}_{2} \mathrm{O}_{3}$ and $\mathrm{Si}$ around $1473 \mathrm{~K}: 2 \mathrm{Al}+$ $\mathrm{N}_{2}(\mathrm{~g}) \rightarrow 2 \mathrm{AlN}, 2 \mathrm{Al}+1.5 \mathrm{SiO}_{2} \rightarrow \mathrm{Al}_{2} \mathrm{O}_{3}+1.5 \mathrm{Si}$; and second exothermic occurs at 1473-1900 K, with the exothermic nitridation of $\mathrm{Si}$ and simultaneous formation of $\beta$-SiAlON: $3 \mathrm{Si}+2 \mathrm{~N}_{2}(\mathrm{~g}) \rightarrow \mathrm{Si}_{3} \mathrm{~N}_{4}, \mathrm{Si}_{3} \mathrm{~N}_{4}+\mathrm{AlN}+\mathrm{Al}_{2} \mathrm{O}_{3} \rightarrow \beta$-SiAlON. Therefore, we define the first and second endothermic processes as at temperatures of 298-1473 K and 1473-1900 K, respectively. In fact, during the entire process for synthesis of $\beta$-SiAlON, there are several endothermic reactions, such as $\mathrm{Al}-\mathrm{Si}$ eutectic (eutectic melting point $570{ }^{\circ} \mathrm{C}$ ), the melting of $\mathrm{Al}$ (melting point $660{ }^{\circ} \mathrm{C}$ ) and $\mathrm{Si}$ (melting point $1414{ }^{\circ} \mathrm{C}$ ), however, these endothermic reactions can be ignored due to small endothermic peaks observed from the temperature curves [30].

Fig. 6 shows the changes in the enthalpy of the raw materials $(\Delta H$ in $\mathrm{kJ} / \mathrm{kg})$, estimated using $\Delta H 1$ and $\Delta H 2$ that correspond to the two major exothermic processes. It is notable that the value of the total enthalpy change $(\Delta H 1+\Delta H 2)$ of sample D45 is higher than that of $\mathrm{N} 12$, and the $\Delta H 1$ value is significantly higher than $\Delta H 2$, mainly because the endothermic region in the former located at temperatures of $298-1473 \mathrm{~K}$, which is longer than the latter that at temperatures of $1473-1900 \mathrm{~K}$.

\subsection{Temperature profiles}

All the temperature profiles analyses were made from the thermocouple T. C. 1 data (see Fig. 1). In fact, the thermocouples are located at the level of the middle of the sample. The typical time-temperature profiles obtained during the CS of 
$\beta$-SiAlON for the D45 and N12 samples by using raw reactants $\mathrm{Si}, \mathrm{Al}$, and $\mathrm{SiO}_{2}$ under $1 \mathrm{MPa}$ nitrogen pressure are shown in Fig. 7. The temperatures rapidly reached the maximum values after ignition, which then decreased at a slow rate for both samples; however, for N12, this process is followed by a longer period of after-burn, in which the temperature decreases, than with D45. This difference arises because of different reaction rates, as discussed in a subsequent section. The maximum measured temperature for D45 and N12 are $1681{ }^{\circ} \mathrm{C}$ and $1505{ }^{\circ} \mathrm{C}$, respectively. The calculated wave propagation velocities by measuring the time that lapsed between the two thermocouples are presented in Table 2. Several times of the repeated experiments show the identical results although there was slightly variance in the maximum measured temperature.

\subsection{Conversion rate}

Fig. 8 shows the first and second derivatives of the temperature profiles acquired during the CS of $\beta$-SiAlON. The first derivatives ((a) and (c)) of the temperature profiles for the two samples show similar trends, although the variation tendency and maximum value are remarkably different. The two peaks in the heating rate $(d T / d t)$ curves indicate a two-stage exothermic process, consistent with the aforementioned reaction mechanism. For sample D45, the first peak in the $d T / d t$ curves is observed at a maximum value of $11^{\circ} \mathrm{C} / \mathrm{s}$, which is lower than that of N12 with a maximum value of $13{ }^{\circ} \mathrm{C} / \mathrm{s}$, as indicated by peaks of 1 and $1^{\prime}$ in (a) and (c), respectively; the second $d T / d t$ peak of D45 rises sharply to reach a value as high as $18^{\circ} \mathrm{C} / \mathrm{s}$ (peak 2 of (a)). However, the second $d T / d t$ peak for N12 (peak $2^{\prime}$ of (c)) approaches a stationary value of $10{ }^{\circ} \mathrm{C} / \mathrm{s}$ and persists for a long period. The significant change in the profile of these curves is attributed to the change in the enthalpies $(\Delta H)$ of the raw materials. Compared with Fig. 6, it is clear that a high value of $\Delta H$ results in a slow heating rate, and a low value contributes to a rapid heating rate.

The reaction rate, $\partial \eta / \partial t$, can generally be calculated from the temperature 
profile using the following equation [31]:

$$
\partial \eta / \partial t=\left[\left(T-T_{0}\right) t_{x}^{-1}+(\partial T / \partial t)-t^{*}\left(\partial^{2} T / \partial t^{2}\right)\right] / \tau_{a d}
$$

where $t^{*}=\alpha / v^{2} ; \alpha$ is the effective thermal diffusivity, $v$ is the wave velocity, and $\tau_{a d}$ denotes the temperature rise under adiabatic conditions. In general, the values of the parameters $t^{*}, t_{x}$, and $\tau_{a d}$ are determined from the profile as follows [32,33]:

$$
\begin{gathered}
1 / t^{*}=1 / t_{r}-1 / t_{d} \\
t_{x}=t_{d}-t_{r} \\
\tau_{a d}=\frac{t_{r}}{t_{d}-t_{r}} \tau\left(t_{1}\right)+\frac{t_{d}}{t_{d}-t_{r}} \tau\left(t_{2}\right)+\frac{1}{t_{d}-t_{r}} \int_{t_{1}}^{t_{2}} \tau d t
\end{gathered}
$$

where $t_{r}$ and $t_{d}$ are the rise and decay times in the remote inert zones of the temperature profile, respectively, and can be determined from the linear slopes of the plot of $\ln \left(T-T_{0}\right)$ vs. $t$ in these two regions, as shown in Fig. 9. The parameter $t_{x}$ is the thermal relaxation time of the system. The calculated parameters $t_{r}, t_{d}, t_{x}$, and $t^{*}$ are listed in Table 3. The values of $t_{1}$ and $t_{2}$ are arbitrarily chosen times located in the remote rise and decay zones, respectively. $\partial T / \partial t$ and $\partial^{2} T / \partial t^{2}$ are the first and second derivatives of the temperature profiles, as shown in Fig. 8. Therefore, the reaction rate is readily computed from the temperature profiles.

Fig. 10 shows the calculated reaction rate $(d \eta / d t)$ and the reacted fraction $(\eta)$ for the CS of $\beta$-SiAlON using the two types of additives. For sample D45, the maximum value of the reaction rate corresponds to a reacted fraction $(\eta)$ of $70 \%$ at $\sim 1587{ }^{\circ} \mathrm{C}$; whereas $\eta$ was only $46 \%$ for sample N12 for the maximum value of $d \eta / d t$ at $\sim 1370{ }^{\circ} \mathrm{C}$. The results indicate that the maximum reaction rate is not achieved at the maximum temperature for both samples. At the maximum measured temperature, for sample D45, $\eta=88 \%$, which indicates that essentially complete conversion is achieved. In contrast, the reaction is only partially completed for sample N12 with $\eta=59 \%$. The lower reaction rate was considered to result from significant heat reduction because of the evaporation of $\mathrm{NaCl}$ during the second exothermic process. As a result, $\eta$ continued to increase as the reaction continued, well past the passage of the combustion wave, and a long after-burn time was required to reach completion of the reaction. 


\subsection{Phase composition of the products}

Fig. 11 shows the XRD patterns of the combustion-synthesized $\beta$-SiAlON powders. No impurity peaks were observed for either of the two samples, and all the observed peaks could be indexed to the pure $\beta$-SiAlON phase. The results indicate that complete nitridation of the $\mathrm{Si}$ was achieved with the respective quantities of $\beta$-SiAlON and $\mathrm{NaCl}$ additives. $\mathrm{NaCl}$ peaks were not detected in the product of $\mathrm{N} 12$, which indicates that their complete evaporation was achieved under the high reaction temperature and separated out of the reaction system [29]. The lattice parameters of the $\beta$-SiAlON phase calculated from these XRD peaks are well matched with those documented in JCPDS 48-1615 $(a=7.635 \AA, c=2.934 \AA)$. Furthermore, the $z$ value of the synthesized $\beta$-SiAlON was calculated using the lattice constants $a$ and $c$ according to the reference method [2]. The calculated parameters are summarized in Table 2.

\subsection{Morphology of products}

Fig. 12 shows the SEM images of the combustion-synthesized $\beta$-SiAlON powders obtained using the two types of additives. The sample D45 that was prepared by adding 45 mass $\%$ of $\beta$-SiAlON powder consisted of ball-like particles and columnar crystals of various sizes, most of which exhibited extensive agglomeration to form large blocks. Compared with sample D45, the rod-like crystals of sample N12, prepared by addition of 12 mass $\% \mathrm{NaCl}$, had larger sizes with lengths $\sim 3 \mu \mathrm{m}$ and diameters $\sim 2 \mu \mathrm{m}$. The formation of large crystals was induced by rapid mass diffusion, precipitation, and crystal growth of $\beta$-SiAlON nuclei caused by the long period of after-burning, as shown in the temperature profile presented in Fig. 7. The crystals of both samples had rounded tips, typical of crystals formed by the vapor-liquid-solid (VLS) process. In this process, a liquid droplet is initially formed, and then reactant molecules in the vapor phase are transported by diffusion to the liquid-solid interface. 
With precipitation and crystal growth, the droplet is detached from the substrate $[34,35]$. When the $\beta$-SiAlON powder was used as the additive, the vapor phase precipitated and grew on the surface of the powders. Solid-state diffusion between the newly formed $\beta$-SiAlON crystals and the added ones provides a source of atoms to fill up the concave areas to diminish the outer surface of the particle, resulting in self-sintering [36]. However, when $\mathrm{NaCl}$ is used as an additive, the melted $\mathrm{NaCl}$ creates a potential diffusion barrier between the $\beta$-SiAlON crystals; hence, sintering of the $\beta$-SiAlON particles could be prevented. The melted $\mathrm{NaCl}$ may then be vaporized because of the high combustion temperature, followed by outward diffusion leaving space between the particles, thus generating well-isolated crystallized particles.

\section{Conclusions}

The reaction characteristics of the CS of $\beta$-SiAlON in a horizontal-type chamber were compared using two types of additives ( $\beta$-SiAlON and $\mathrm{NaCl})$. The results revealed that the various additives produced different changes in the enthalpies of the raw materials, which affected the reaction rate and morphology of the products. With addition of the $\beta$-SiAlON powder to the starting materials, the reaction was largely completed within the combustion front at the maximum temperature; in contrast, a relatively slow conversion rate was achieved (with $\eta=58.7 \%$ ) when 12 mass $\% \mathrm{NaCl}$ was used as the additive. This difference is attributed to the high latent heat of evaporation of $\mathrm{NaCl}$, with consequent occurrence of a long after-burn effect that is beneficial for the formation of well-developed rod-like crystals.

The originality of this work is to analyze kinetic of the reaction on propagation based on a model established by Boddington, which shows that different additives give rise to different reaction rate and degree of conversion. These conclusions are very important, since they permit a better approach to the complexity of CS processes. We are now able to better control any reaction system, and thus the application of CS. 
Additionally, the comparative analysis indicates that $\mathrm{NaCl}$ is a potential additive for industrial-scale production of $\beta$-SiAlON powders, which is a more economic and energy-efficient synthesis process. This new process has several notable advantages: the production efficiency should be greatly improved because of the small amount of additive, a product with a fine grain size is obtained, and the high cost of postsynthesis treatments such as crushing and milling is avoided. Therefore, the overall production cost of $\beta$-SiAlON can be significantly reduced, and the lower price of these $\beta$-SiAlON powders may open up new applications for these materials.

\section{Acknowledgements}

This research was financially supported by a Grant-in-Aid for Scientific Research on Priority Areas (B) (24360313, Salt-assisted Combustion Synthesis of SiAlON nano-powders). The authors thank Dr. Sakurai and Mr. Harada of Combustion Synthesis Co., Ltd. for the valuable discussions. 


\section{References}

[1] K.H. Jack, Sialons and related nitrogen ceramics, J. Mater. Sci. 11 (1976) $1135-1158$.

[2] T. Ekström, P.O. Käll, M. Nygren, P.O. Olssen, Dense single-phase $\beta$-sialon ceramics by glass-encapsulated hot isostatic pressing, J. Mater. Sci. 24 (1989) 1853-1861.

[3] T. Ekström, M. Nygren, SiAlON Ceramics, J. Am. Ceram. Soc. 75[2] (1992) 259-276.

[4] D.-H. Kim, J. Ryu, S.-Y. Cho, Light emitting properties of SiAlON:Eu ${ }^{2+}$ green phosphor, Appl. Phys. A 102 (2011) 79-83.

[5] N. Hirosaki, R.-J. Xie, K. Kimoto, T. Sekiguchi, Y. Yamamoto, T. Suehiro, M. Mitomo, Characterization and properties of green-emitting $\beta-\mathrm{SiAlON}: \mathrm{Eu}^{2+}$ powder phosphors for white light-emitting diodes, Appl. Phys. Lett. 86 (2005) 211905-211903.

[6] R.-J. Xie, N. Hirosaki, H.-L. Li, Y.Q. Li, M. Mitomo, Synthesis and photoluminescence properties of $\beta$-sialon: $\mathrm{Eu}^{2+}\left(\mathrm{Si}_{6-\mathrm{z}} \mathrm{Al}_{\mathrm{z}} \mathrm{O}_{\mathrm{z}} \mathrm{N}_{8-\mathrm{z}}: \mathrm{Eu}^{2+}\right): \mathrm{A}$ promising green oxynitride phosphor for white light-emitting diodes, J. Electrochem. Soc. 154 (2007) J314-J319.

[7] C. Zhang, R. Janssen, N. Claussen, Pressureless sintering of $\beta$-SiAlON with improved green strength by using metallic Al powder, Mater. Lett. 57 (2003) $3352-3356$.

[8] S.-L. Hwang, I.-W. Chen, Reaction hot pressing of $\alpha^{\prime}$ - and $\beta^{\prime}-\mathrm{SiAlON}$ ceramics, J. Am. Ceram. Soc. 77 (1994) 165-171.

[9] K.J.D. MacKenzie, D.V. Barneveld, Carbothermal synthesis of $\beta$-SiAlON from mechanochemically activated precursors, J. Eur. Ceram. Soc. 26 (2006) 209-215.

[10] J. Li, H. Ma, Q. Fang, Synthesis of prismatic beta-sialon from the precursor of SBA-15 incorporated with $\mathrm{Al}\left(\mathrm{NO}_{3}\right)_{3}$ via carbothermal reduction nitridation, Ceram. Inter. 34 (2008) 1791-1795. 
[11] A.G. Merzhanov, Combustion processes that synthesize materials, J. Mater. Process. Tech. 56 (1996) 222-241.

[12] A.G. Merzhanov, History and recent developments in SHS, Ceram. Inter. 21 (1995) 371-379.

[13] I. Perraud, R.M. Ayral, F. Rouessac, A. Ayral, Combustion synthesis of porous $\mathrm{ZnO}$ monoliths for sulfur removal, Chem. Eng. J. 200-202 (2012) 1-9.

[14] L.J. Groven, J.A. Puszynski, Combustion synthesis and characterization of nickel aluminide-carbon nanotube composites, Chem. Eng. J. 183 (2012) 515-525.

[15] I.P. Parkin, G. Elwin, L.F. Barquin, Q.T. Bui, Q.A. Pankhurst, A.V. Komarov, Y.G. Morozov, Self-propagating high temperature synthesis of hexagonal ferrites $\mathrm{MFel}_{2} \mathrm{O}_{19}(\mathrm{M}=\mathrm{Sr}, \mathrm{Ba})$, Adv. Mater. 9 (1997) 643-645.

[16] D. Vallauri, V.A. Shcherbakov, A.V. Khitev, F.A. Deorsola, Study of structure formation in $\mathrm{TiC}_{-} \mathrm{TiB}_{2}-\mathrm{MexOy}$ ceramics fabricated by SHS and densification, Acta Mater. 56 (2008) 1380-1389.

[17] J. Niu, T. Akiyama, X. Yi, I. Nakatsugawa, Combustion synthesis of high-purity $\beta$-SiAlON fine powders using natural kaolin, AIChE J. 59 (2013) 19-22.

[18] N. Pradeilles,, M. C. Record, D. Granier, R.M. Marin-Ayral, Synthesis of $\beta$-SiAlON: A combined method using sol-gel and SHS processes, Ceram. Inter. 34 (2008) 1189-1194.

[19] K.L. Smirnov, I.P. Borovinskaya, SHS and some properties of SiAlON ceramics, Key Eng. Mater. 217 (2001) 159-164.

[20] K. Aoyagi, T. Hiraki, R. Sivakumar, T. Watanabe, T. Akiyama, Mechanically activated combustion synthesis of $\beta-\mathrm{Si}_{6-\mathrm{z}} \mathrm{Al}_{\mathrm{z}} \mathrm{O}_{\mathrm{z}} \mathrm{N}_{8-\mathrm{z}}(\mathrm{z}=1-4)$, J. Am. Ceram. Soc. 90 (2007) 626-628.

[21] K. Aoyagi, T. Hiraki, R. Sivakumar, T. Watanabe, T. Akiyama, A new route to synthesize $\beta-\mathrm{Si}_{6-z} \mathrm{Al}_{z} \mathrm{O}_{z} \mathrm{~N}_{8-z}$ powders, J. Alloys. Compd. 441 (2007) 236-240.

[22] X. Yi, T. Akiyama, Mechanical-activated, combustion synthesis of $\beta$-SiAlON, J. Alloys. Compd. 495 (2010) 144-148.

[23] X. Yi, K. Watanabe, T. Akiyama, Fabrication of dense $\beta$-SiAlON by a combination of combustion synthesis (CS) and spark plasma sintering (SPS), 
Intermetallics 18 (2010) 536-541.

[24] K. Aoyagi, R. Sivakumar, X. Yi, T. Watanabe, T. Akiyama, effect of diluents on high purity $\beta$-SiAlONs by mechanically activated combustion synthesis, J. Ceram. Soc. Japan 117 (2009) 777-779.

[25] M. Shahien, M. Radwan, S. Kirihara, Y. Miyamoto, T. Sakurai, Combustion synthesis of single-phase $\beta$-sialons $(z=2-4)$, J. Eur. Ceram. Soc. 30 (2010) 1925-1930.

[26] H.H. Nersisyan, J.H. Lee, C.W. Won, Self-propagating high-temperature synthesis of nano-sized titanium carbide powder, J. Mater. Res. 17 (2002) 2859-2864.

[27] H.E. Çamurlu, F. Maglia, Preparation of nano-size $\mathrm{ZrB}_{2}$ powder by self-propagating high-temperature synthesis, J. Eur. Ceram. Soc. 29 (2009) $1501-1506$

[28] A.K. Khanra, L.C. Pathak, S.K. Mishra, M.M. Godkhindi, Effect of $\mathrm{NaCl}$ on the synthesis of $\mathrm{TiB}_{2}$ powder by a self-propagating high-temperature synthesis technique, Mater. Lett. 58 (2004) 733-738.

[29] J. Niu, X. Yi, I. Nakatsugawa, T. Akiyama, Salt-assisted combustion synthesis of $\beta$-SiAlON fine powders, Intermetallics 35 (2013) 53-59.

[30] X. Yi, J. Niu, T. Nakamura, T. Akiyama, Reaction mechanism for combustion synthesis of $\beta$-SiAlON by using $\mathrm{Si}, \mathrm{Al}$, and $\mathrm{SiO}_{2}$ as raw materials, J. Alloys. Compd. 561 (2013) 1-4.

[31] T. Boddington, P.G. Laye, J. Tipping, D. Whalley, Kinetic analysis of temperature profiles of pyrotechnic systems, Combust. Flame 63 (1986) $359-368$.

[32] S.D. Dunmead, Z.A. Munir, J.B. Holt, Temperature profile analysis in combustion synthesis: I, theory and background, J. Am. Ceram. Soc. 75 (1992) 175-179.

[33] S.D. Dunmead, Z.A. Munir, J.B. Holt, Temperature profile analysis in combustion synthesis: II, experimental observations, J. Am. Ceram. Soc. 75 (1992) 180-188. 
[34] Y. Wu, H. Zhuang, F. Wu, Mechanism of the formation of $\beta$-Sialon by self-propagating high-temperature synthesis, J. Mater. Res. 13 (1998) 166-172.

[35] J.H. Yang, L.S. Han, Y.X. Chen, G.H. Liu, Z.M. Lin, J.T. Li, Effects of pelletization of reactants and diluents on the combustion synthesis of $\mathrm{Si}_{3} \mathrm{~N}_{4}$ powder, J. Alloys. Compd. 511 (2012) 81-84.

[36] J. Wiley, Sons, Sintering Theory and Practice, New York NY (1996) 225-213. 


\section{Figure captions}

Fig. 1 Schematic diagram of horizontal-type combustion synthesis (CS) apparatus.

Fig. 2 Experimental procedure for $\mathrm{CS}$ of $\beta$-SiAlON using (a) 45 mass $\% \beta$-SiAlON product as diluent, which was first CSed with addition of commercial SiAlON, and (b) 12 mass $\% \mathrm{NaCl}$.

Fig. 3 SEM images of raw materials for CS of $\beta$-SiAlON: (a) D45, (b) N12.

Fig. 4 Particle size distribution of the raw materials for CS of $\beta$-SiAlON: (a) D45, (b) N12.

Fig. 5 Heat content of $\beta-\mathrm{SiAlON}$ and $\mathrm{NaCl}$ during $\mathrm{CS}$. Zones I and II were determined based on previous studies (Ref. 29 and 30).

Fig. 6 Changes in enthalpy of raw materials $\Delta H(\mathrm{~kJ} / \mathrm{kg})$ for CS of $\beta$-SiAlON powders with addition of $\beta$-SiAlON and $\mathrm{NaCl}$, calculated from Fig. 3; "1" and " 2 " indicate first and second endothermic stages.

Fig. 7 Temperature profiles (T. C. 1) recorded during CS of $\beta$-SiAlON: (a) D45, (b) N12.

Fig. 8 First derivative $d T / d t$ (a and c) and second derivative $d^{2} T / d t^{2}$ (b and d) of temperature profiles during CS of $\beta$-SiAlON, D45 (a and b) and N12 (c and d).

Fig. 9 Plots of $\ln \left(T-T_{0}\right)$ vs. $t$ for inert zone of temperature profiles, rise zone (a and c) and decay zone (b and d).

Fig. 10 Time dependence of reaction rate $(d \eta / d t)$ and fraction reacted $(\eta)$ for CS of $\beta$-SiAlON: (a) D45 and (b) N12.

Fig. 11 XRD patterns of CSed $\beta$-SiAlON powders, (a) D45 and (b) N12.

Fig. 12 SEM images of CSed $\beta$-SiAlON powders: (a) D45 and (b) N12. 
Table 1

Specific heat capacity and heat capacity formula of $\beta-\mathrm{SiAlON}$ and $\mathrm{NaCl}$

\begin{tabular}{|c|c|c|c|c|c|c|}
\hline Materials & $\begin{array}{c}\mathrm{Cp}(\mathrm{kJ} / \mathrm{kg} \cdot \mathrm{K}) \\
(\mathrm{T}=298 \mathrm{~K})\end{array}$ & \multicolumn{5}{|c|}{$(\mathrm{kJ} / \mathrm{kg} \cdot \mathrm{K})$} \\
\hline$\beta-\mathrm{SiAlON}$ & 0.731 & \multicolumn{5}{|c|}{$-0.17304+3.99 * 10^{-3} \mathrm{~T}-3.51967 * 10^{-6} \mathrm{~T}^{2}+1.05768 * 10^{-9} \mathrm{~T}^{3}$} \\
\hline \multirow[t]{6}{*}{$\mathrm{NaCl}$} & \multirow[t]{6}{*}{0.861} & \multicolumn{5}{|c|}{$\mathrm{A}+\mathrm{B} * 10^{-3} \mathrm{~T}+\mathrm{C}^{*} 10^{5} \mathrm{~T}^{-2}+\mathrm{D} * 10^{-6} \mathrm{~T}^{2}$} \\
\hline & & A & B & $\mathrm{C}$ & $\mathrm{D}$ & $\mathrm{T}$ \\
\hline & & 0.96328 & -0.2227 & -0.05857 & 0.374074 & $(298 \leq \mathrm{T} \leq 900 \mathrm{~K})$ \\
\hline & & 1.003319 & -0.30512 & -0.08372 & 0.42005 & $900 \leq \mathrm{T} \leq 1073$. \\
\hline & & -0.43311 & 1.303886 & 6.810277 & -0.30219 & $1073 \leq \mathrm{T} \leq 1500$ \\
\hline & & 1.145458 & 0 & 0 & 0 & $1500 \leq \mathrm{T} \leq 2500$ \\
\hline
\end{tabular}


Table 2

Characteristic parameters calculated from samples

\begin{tabular}{ccccc}
\hline Sample & Wave velocity & \multicolumn{2}{c}{ Lattice constant $(\AA)$} & Calculated \\
\cline { 3 - 4 } & $(\mathrm{mm} / \mathrm{s})$ & $\mathrm{a}$ & $\mathrm{c}$ & z value \\
\hline D45 & 0.168 & 7.6350 & 2.9331 & 1.05 \\
$\mathrm{~N} 12$ & 0.185 & 7.6310 & 2.9309 & 0.94 \\
\hline
\end{tabular}


Table 3

Parameters calculated from temperature profiles

\begin{tabular}{cccccc}
\hline Sample & $\mathrm{t}_{\mathrm{r}}(\mathrm{s})$ & $\mathrm{t}_{\mathrm{d}}(\mathrm{s})$ & $\mathrm{t}_{\mathrm{x}}(\mathrm{s})$ & $\mathrm{t}^{*}(\mathrm{~s})$ & $\tau_{\mathrm{ad}}(\mathrm{K})$ \\
\hline $\mathrm{D} 45$ & 19.75 & 363.64 & 343.89 & 20.89 & 2040 \\
$\mathrm{~N} 12$ & 11.19 & 483.09 & 471.90 & 11.46 & 2271 \\
\hline
\end{tabular}

$\mathrm{t}_{\mathrm{r}}$ : inert rise time

$t_{d}:$ inert decay time

$t_{x}:$ thermal relaxation time of system

$1 / \mathrm{t}^{*}=1 / \mathrm{t}_{\mathrm{r}}-1 / \mathrm{t}_{\mathrm{d}}$

$\tau_{\mathrm{ad}}:$ temperature rise under adiabatic conditions 


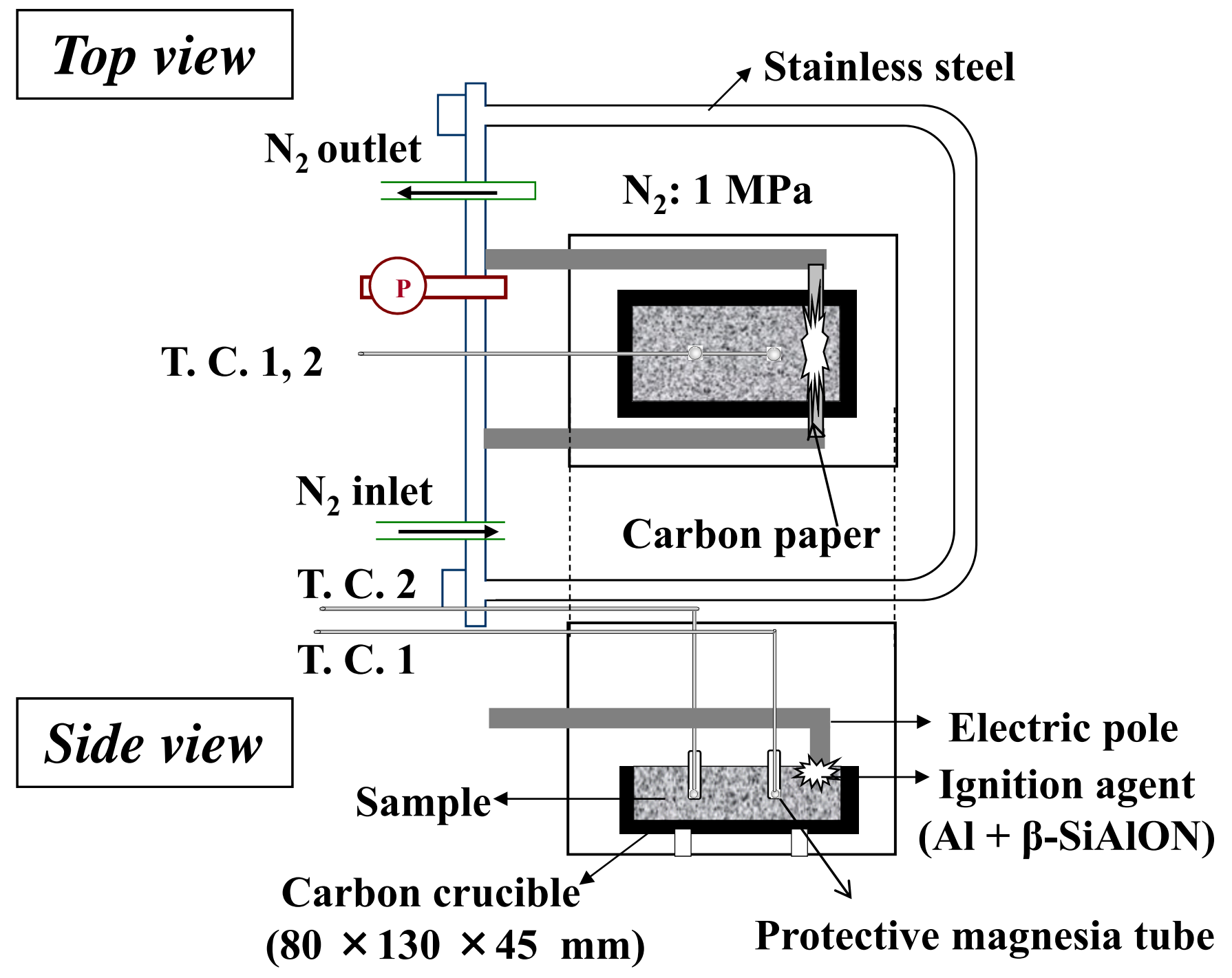

Fig. 1 
(a) Conventional method

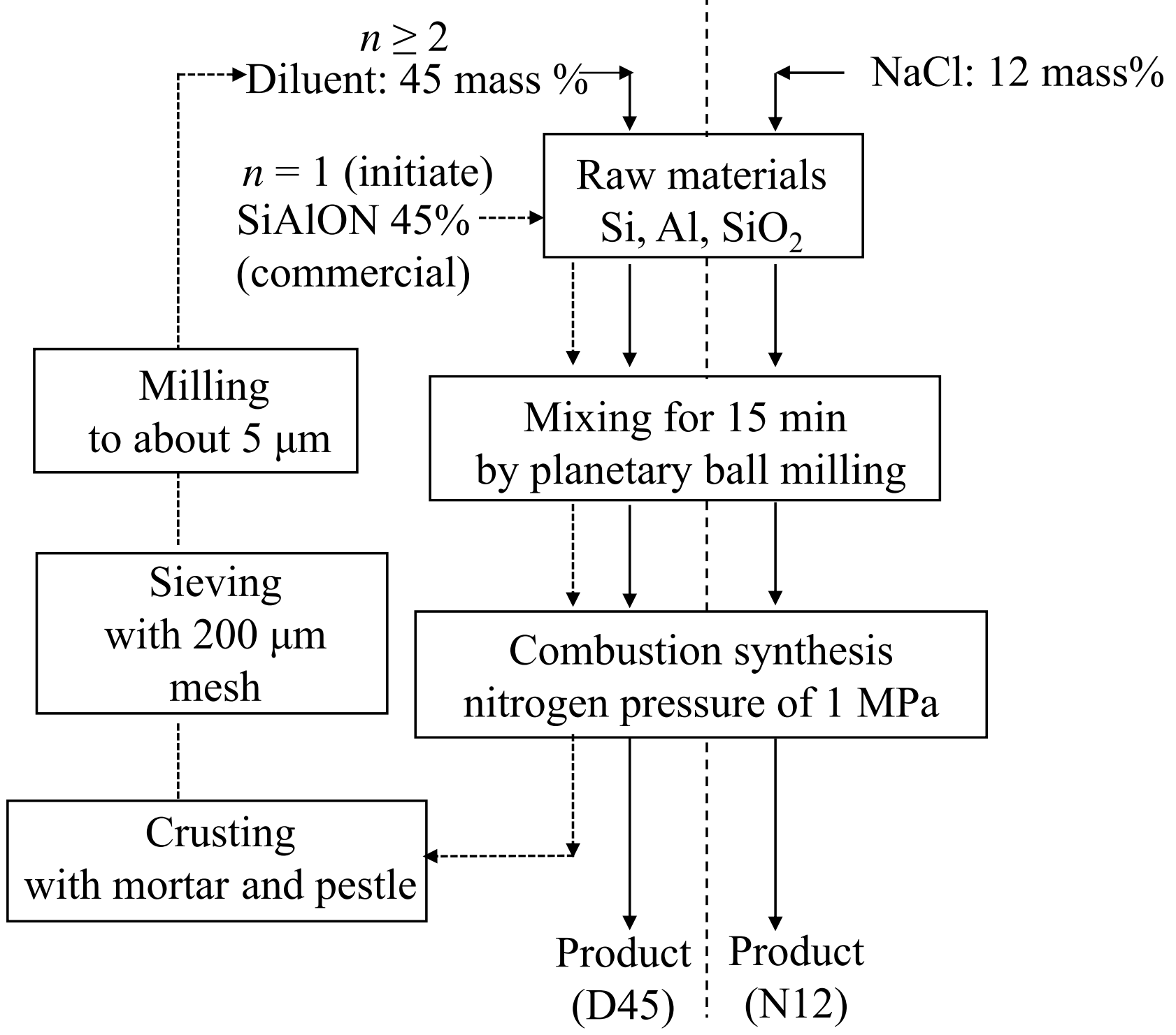

Fig. 2 

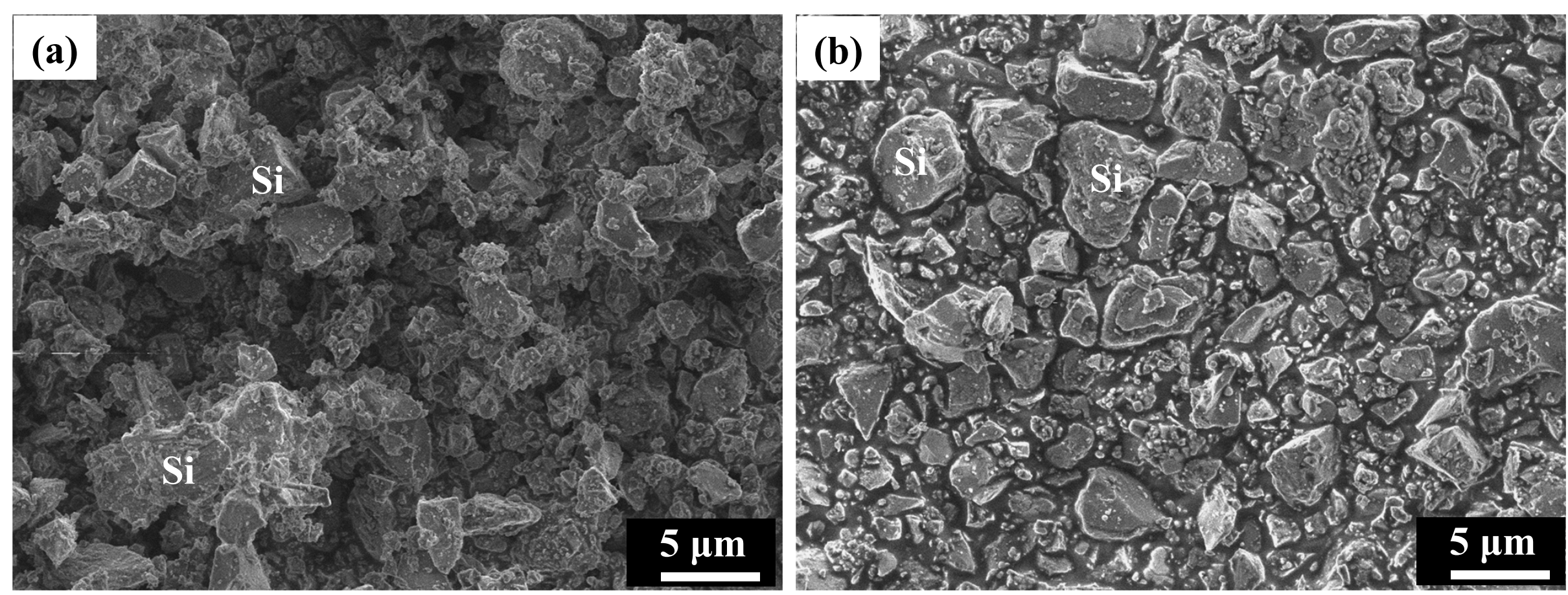

Fig. 3 
(a)

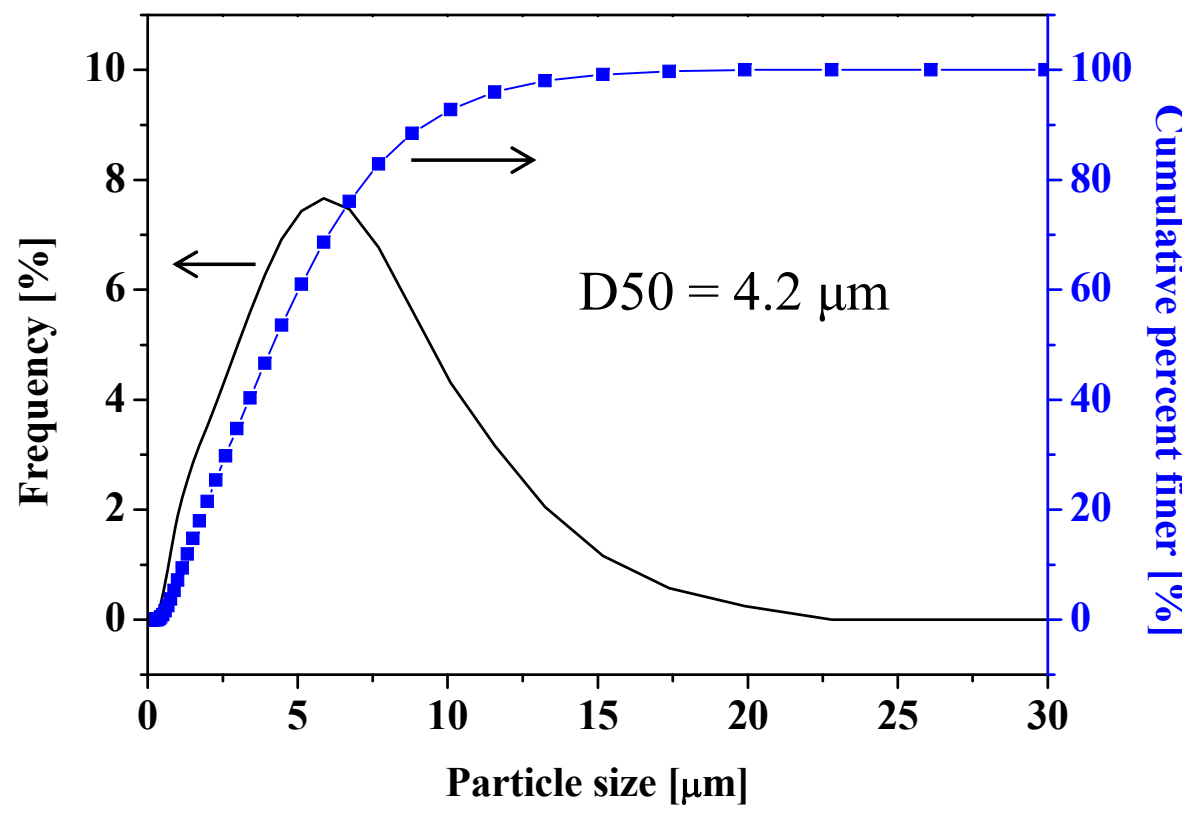

(b)

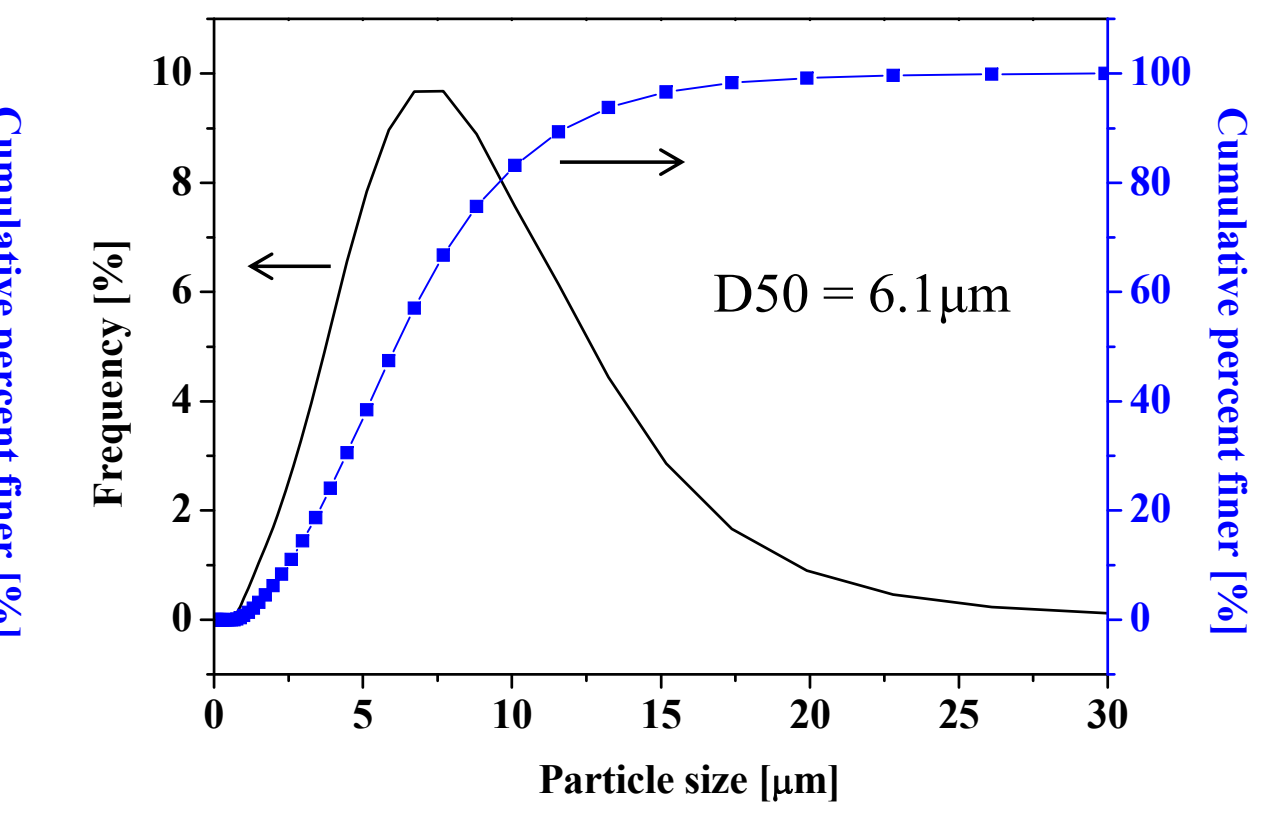

Fig. 4 


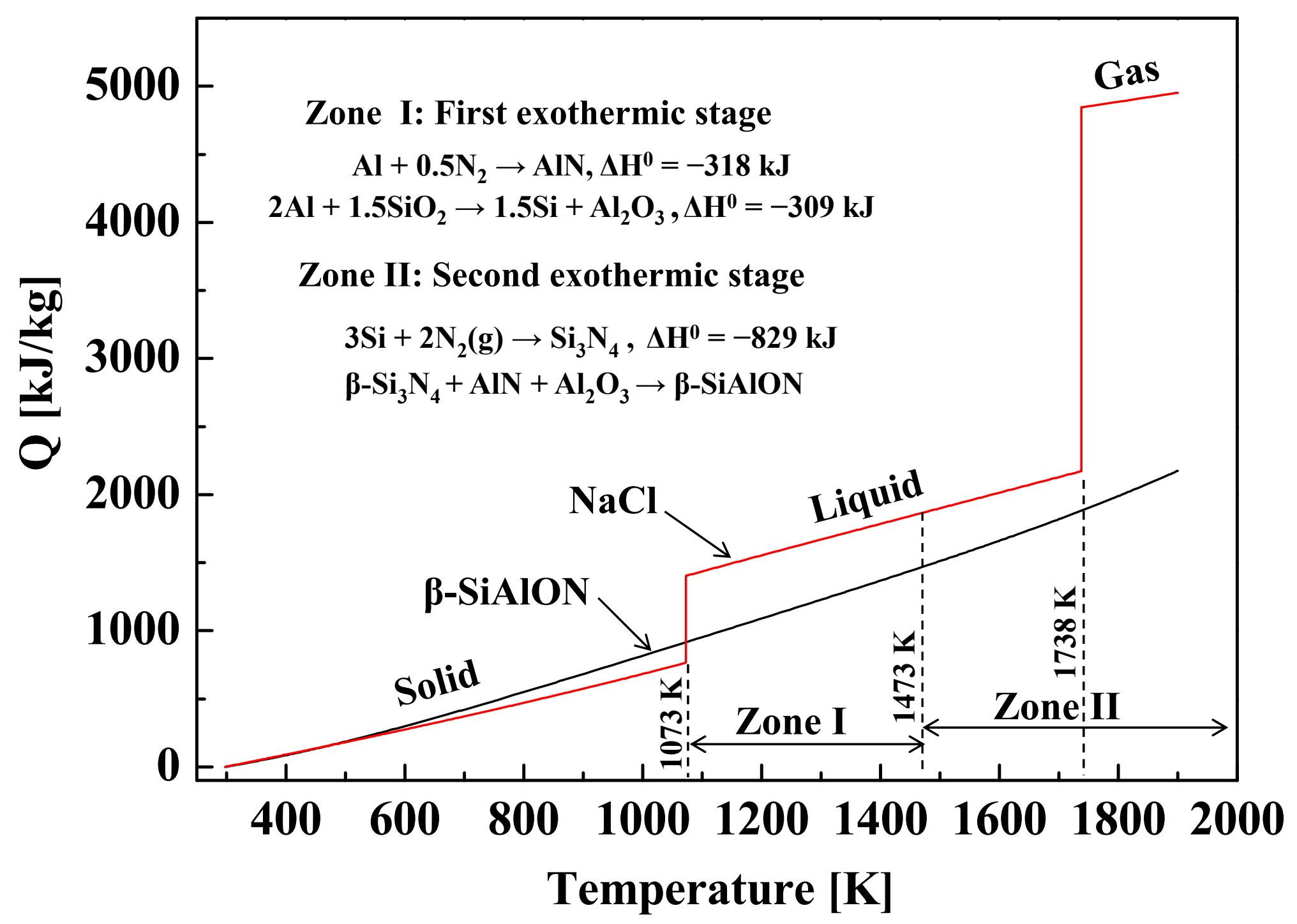

Fig. 5 


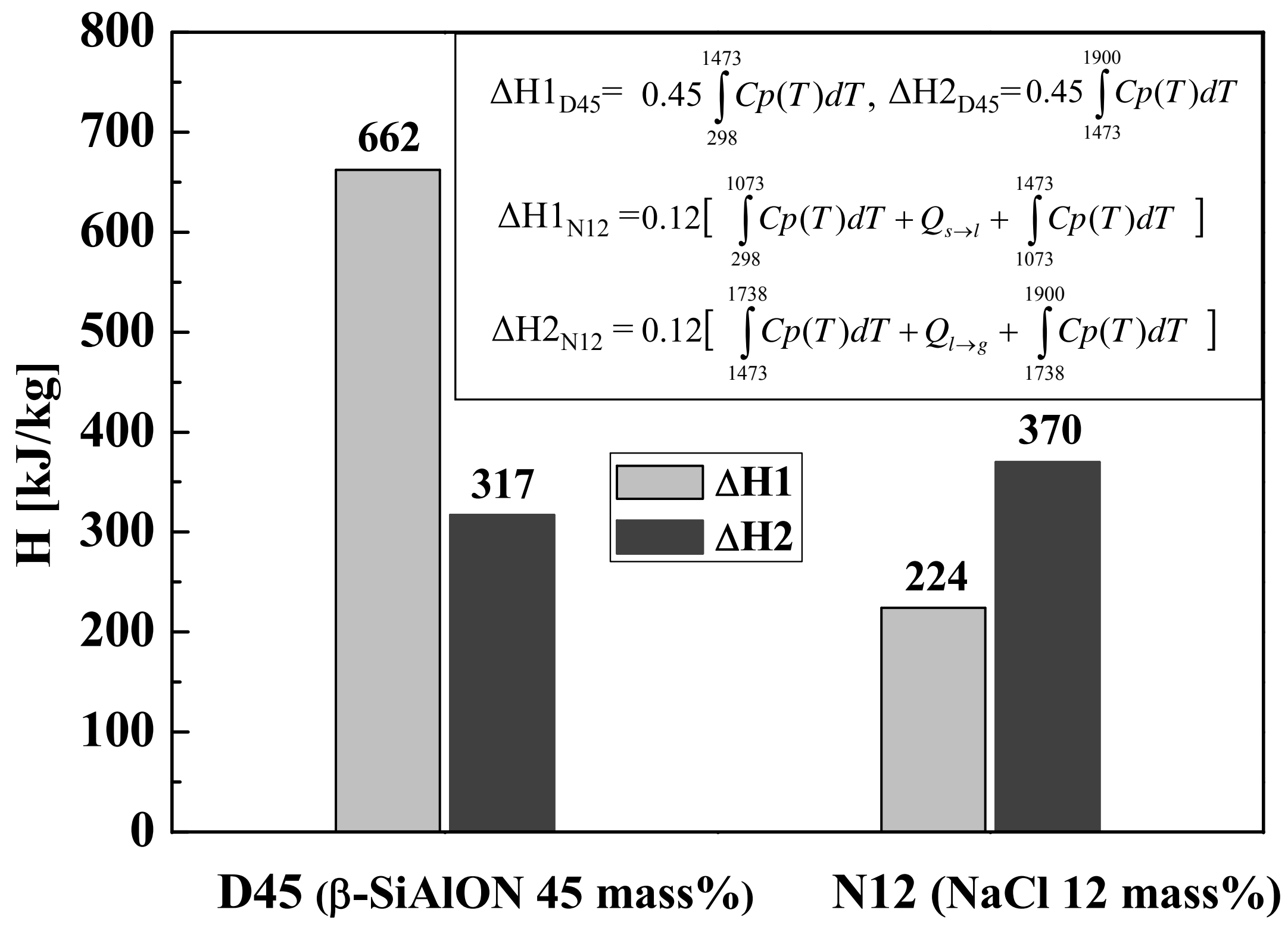

Fig. 6 
(a)

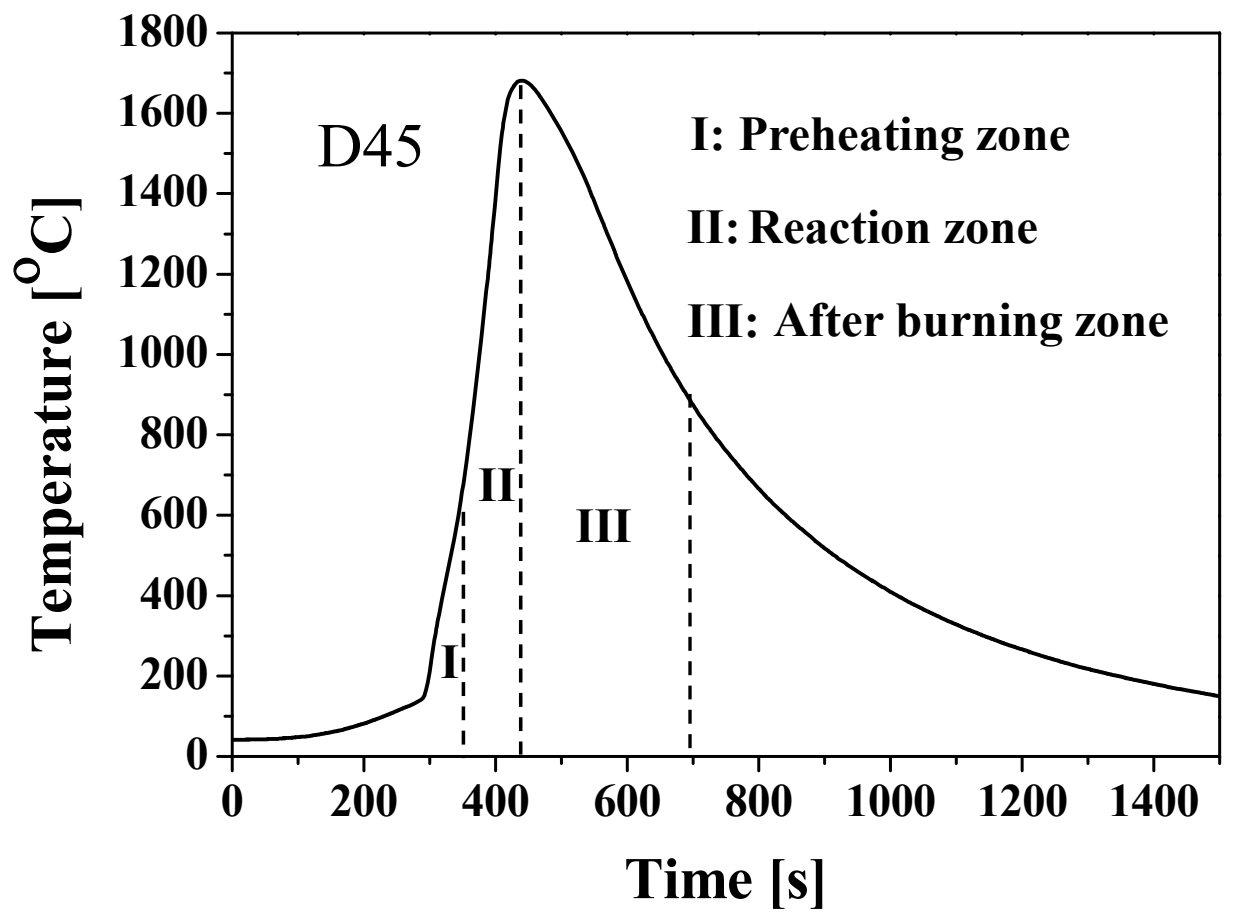

(b)

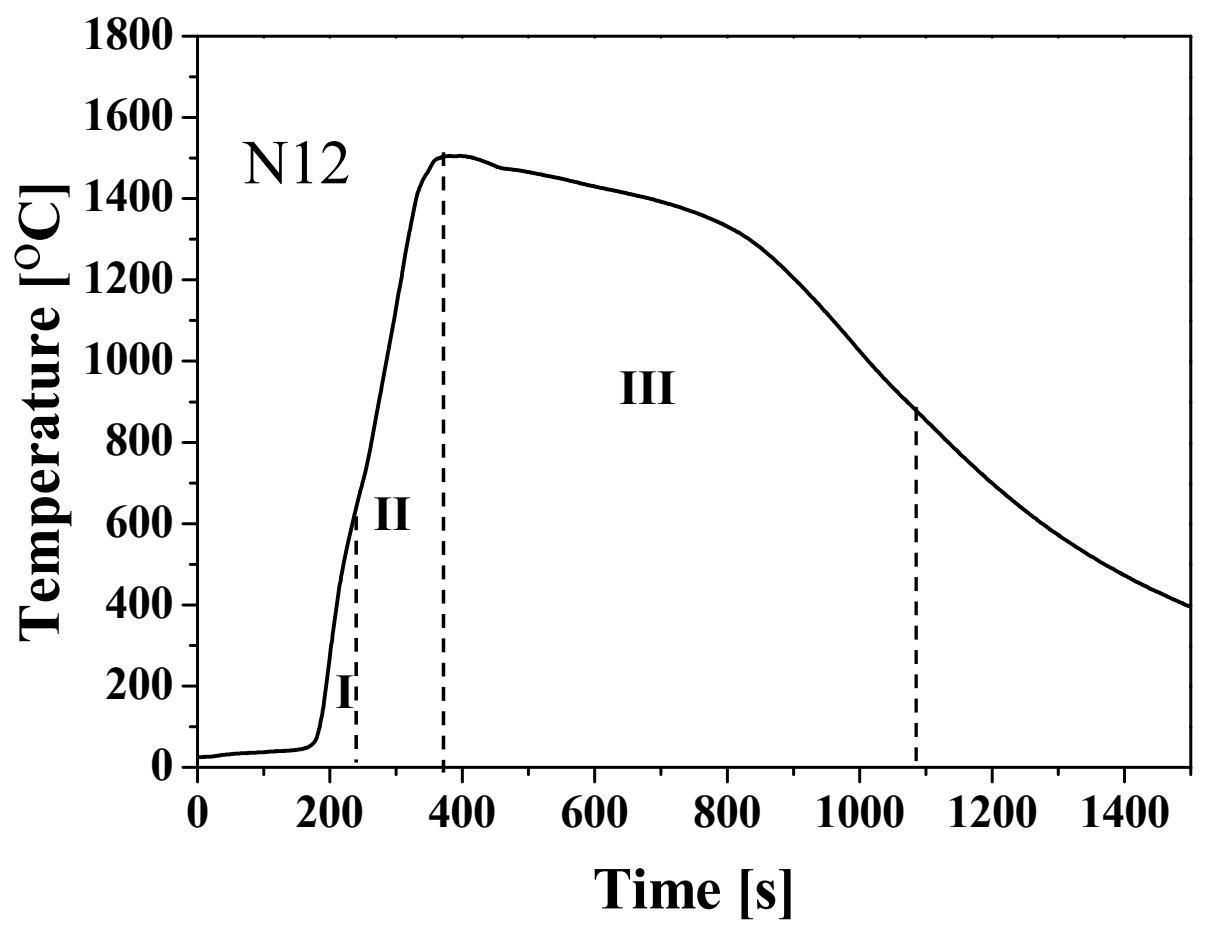

Fig. 7 

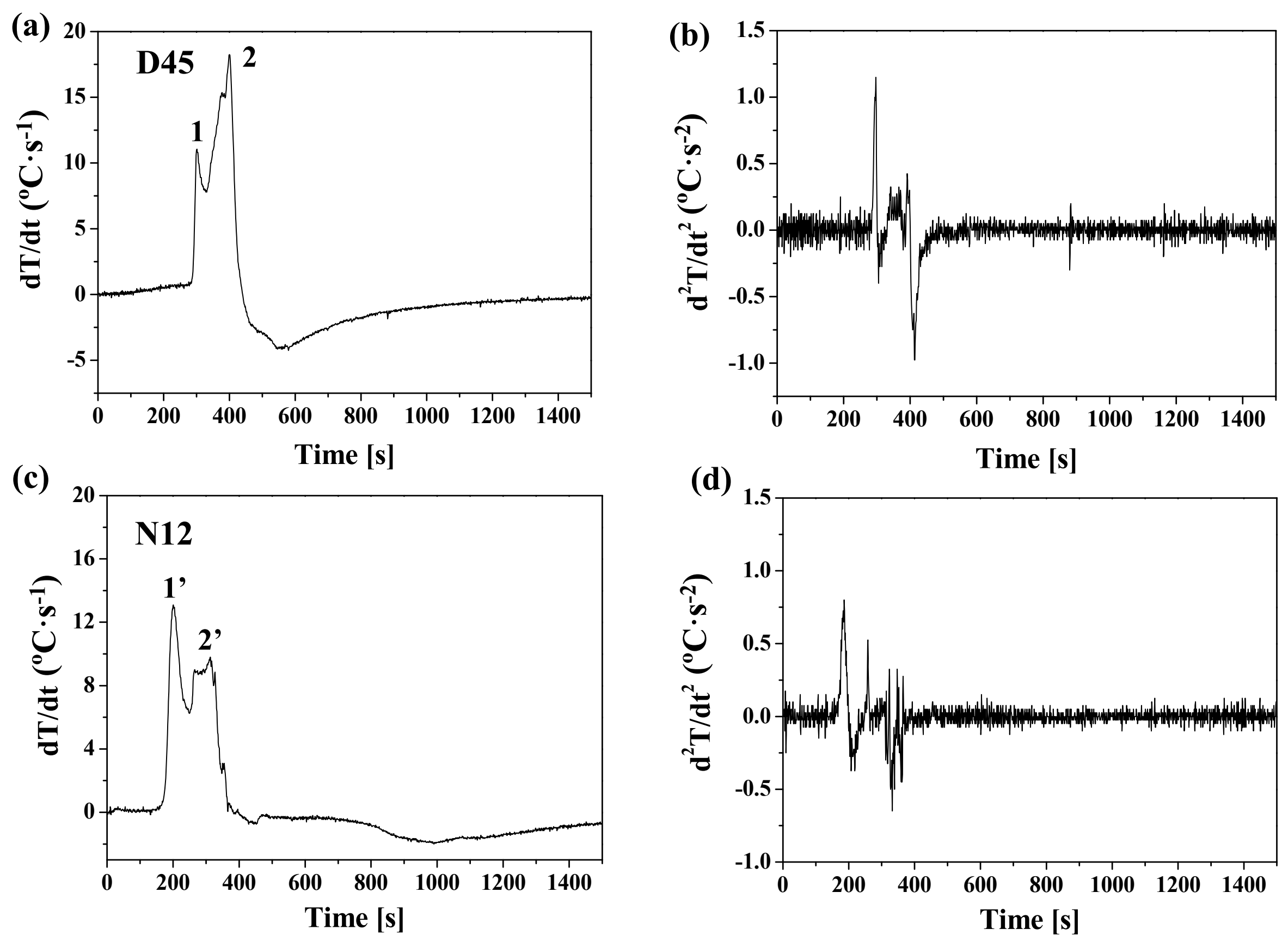

Fig. 8 
(a)

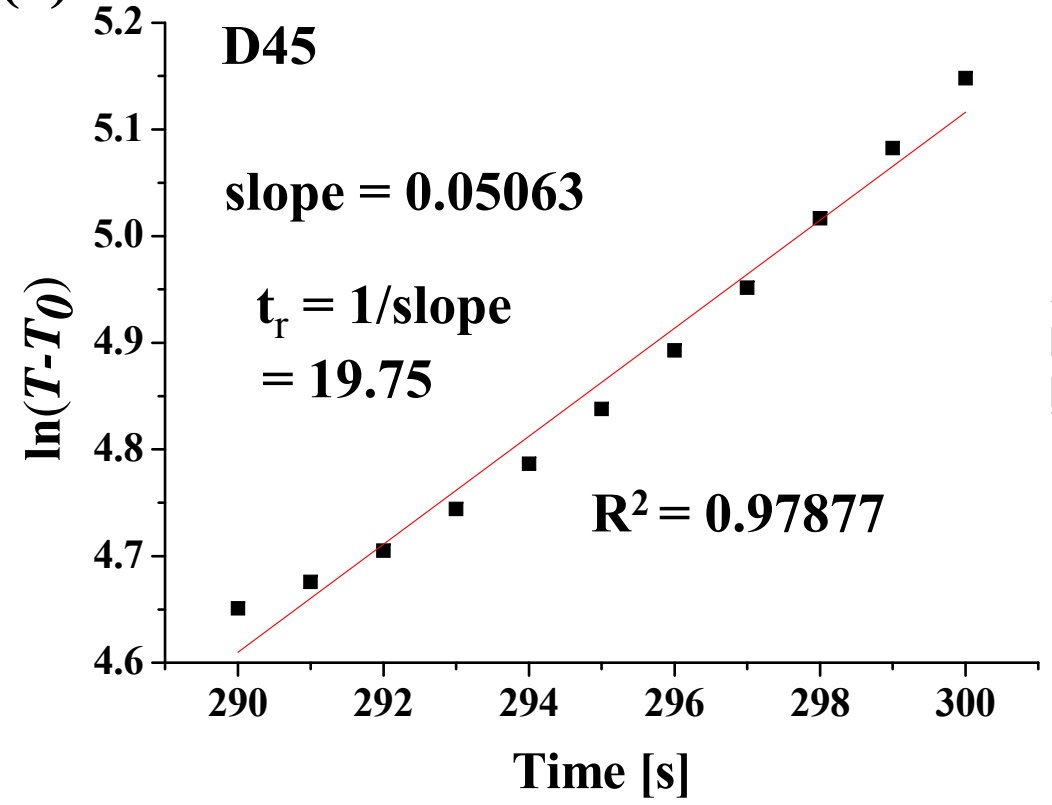

(c)

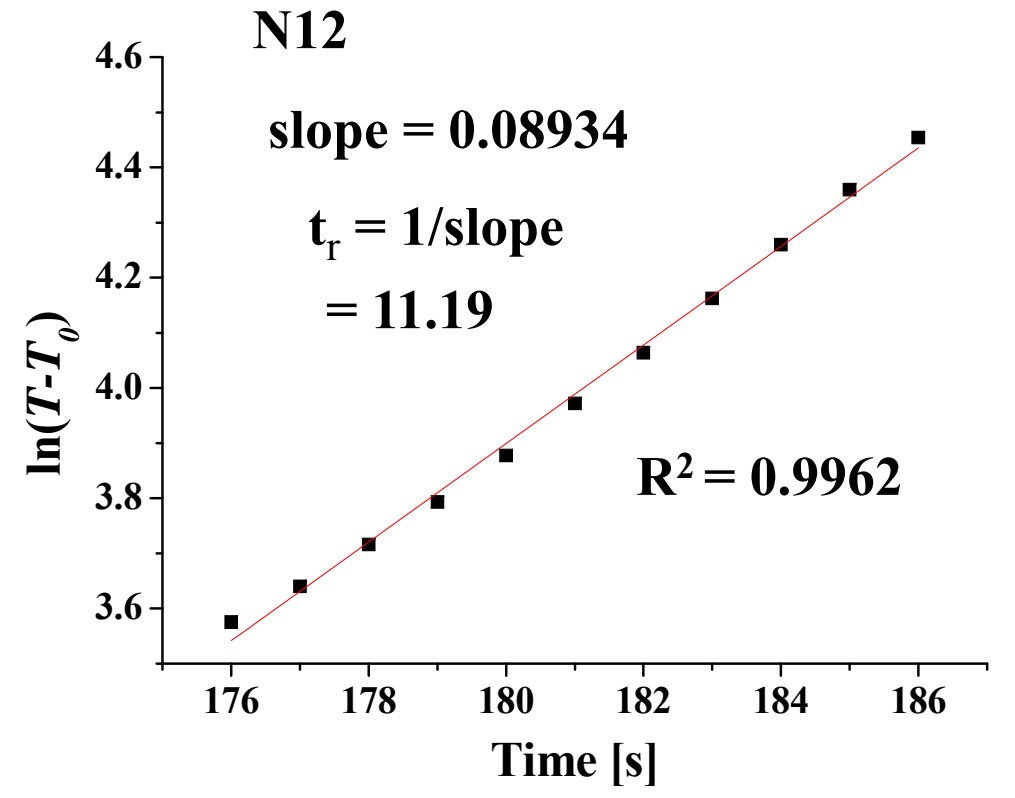

(b)

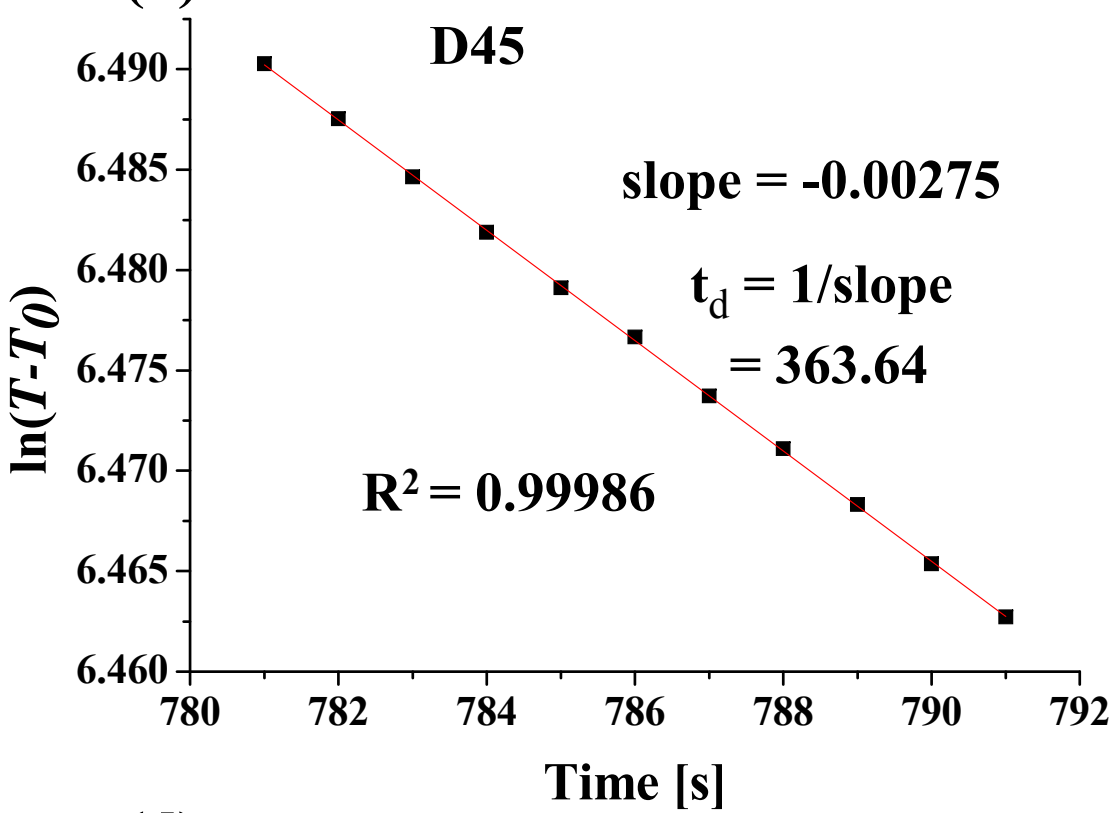

(d)

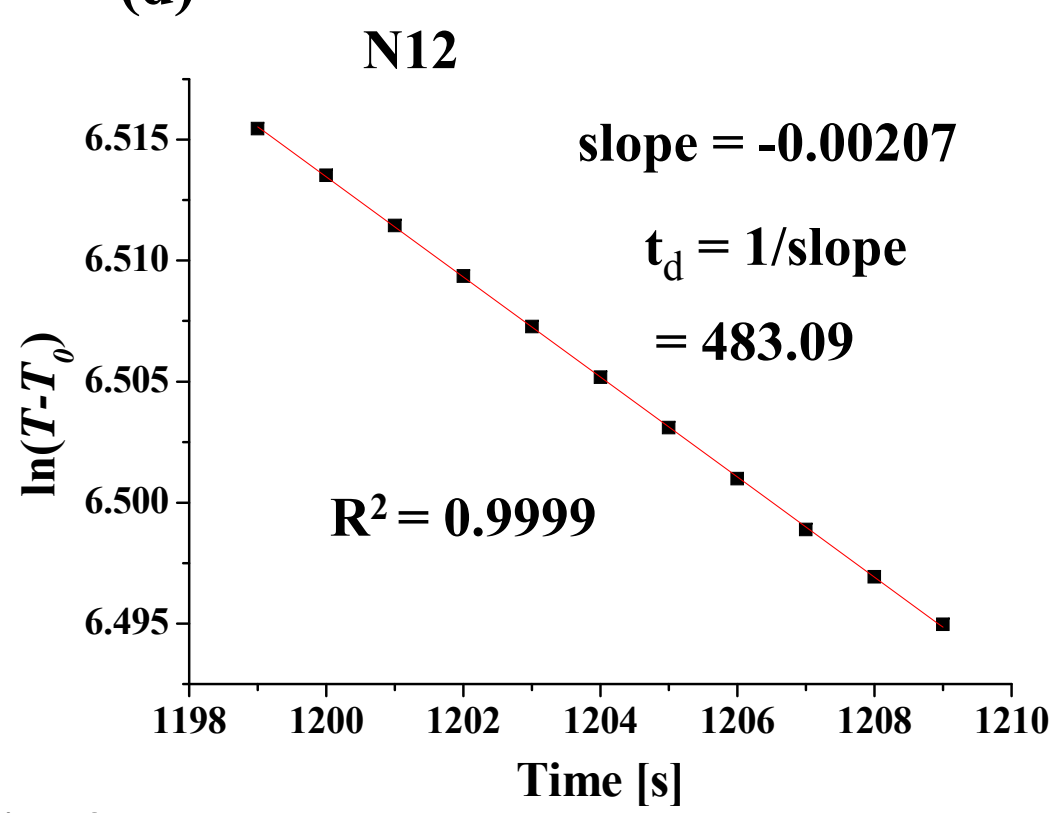

Fig. 9 


\section{(a) D45}

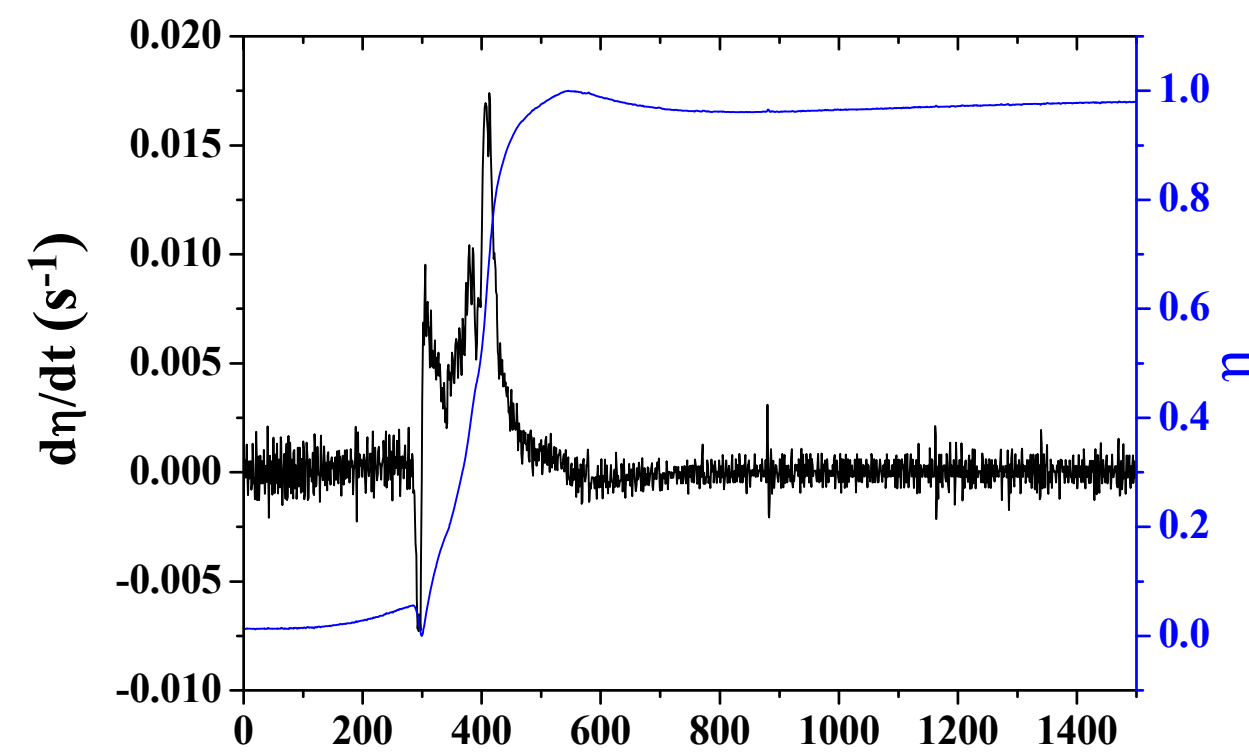

Time [s] (b) $\mathrm{N} 12$

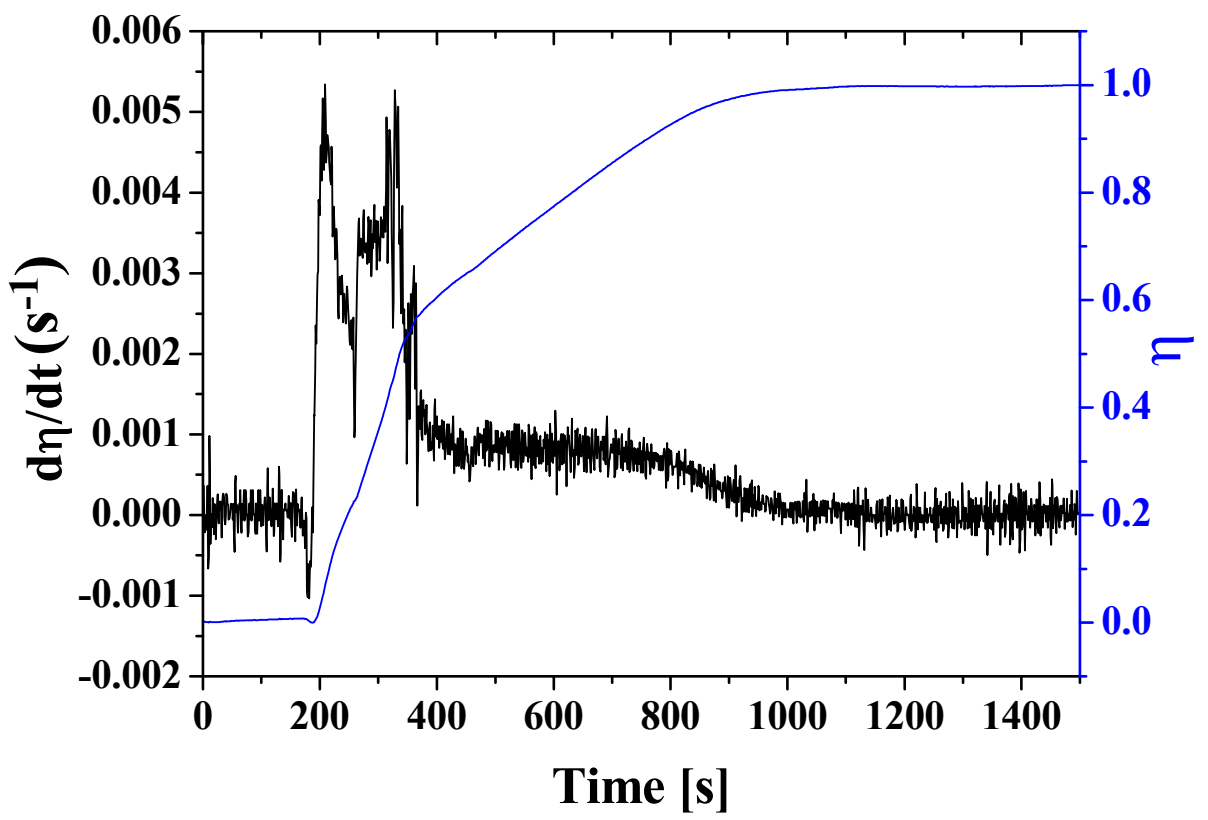

Fig. 10 


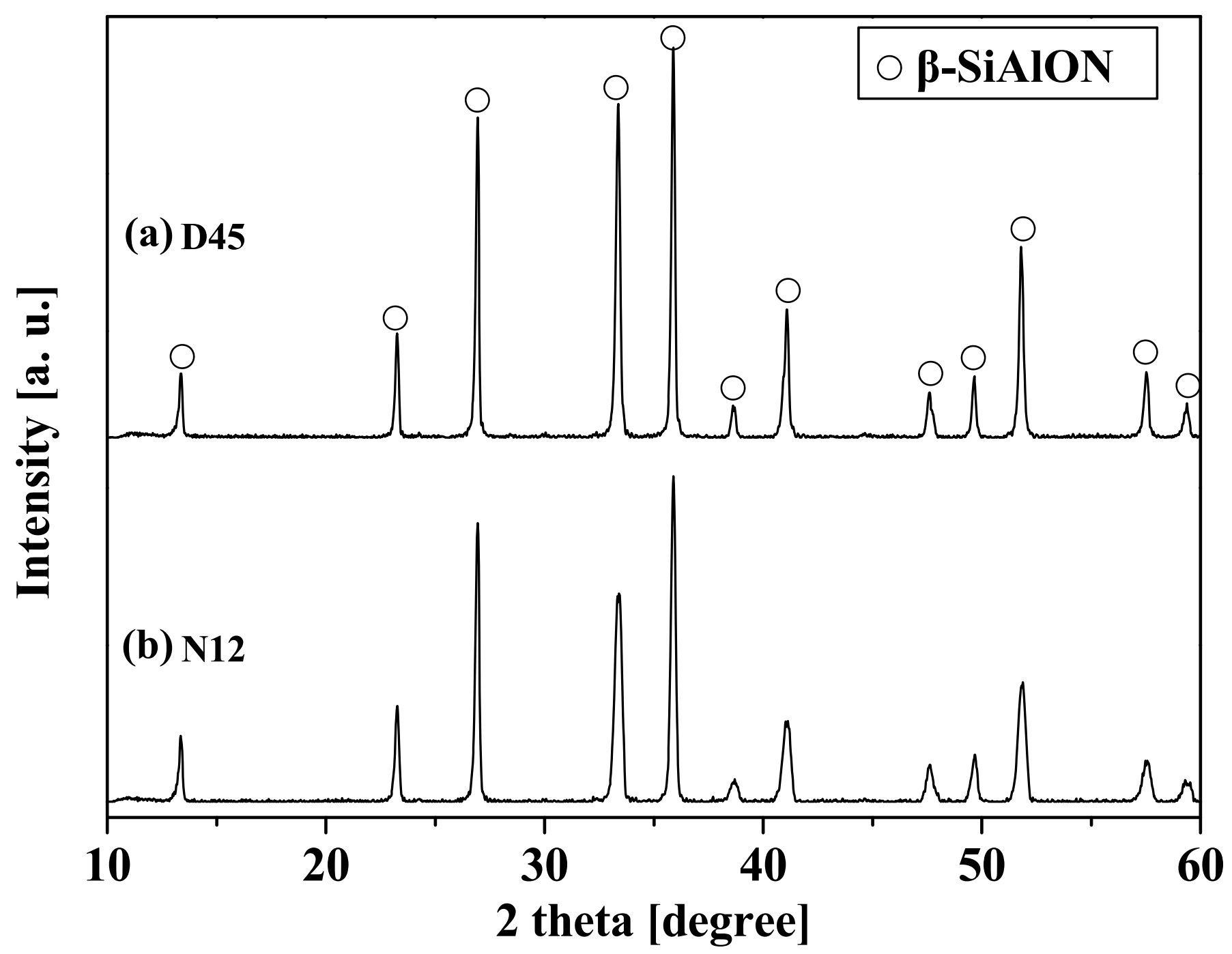

Fig. 11 


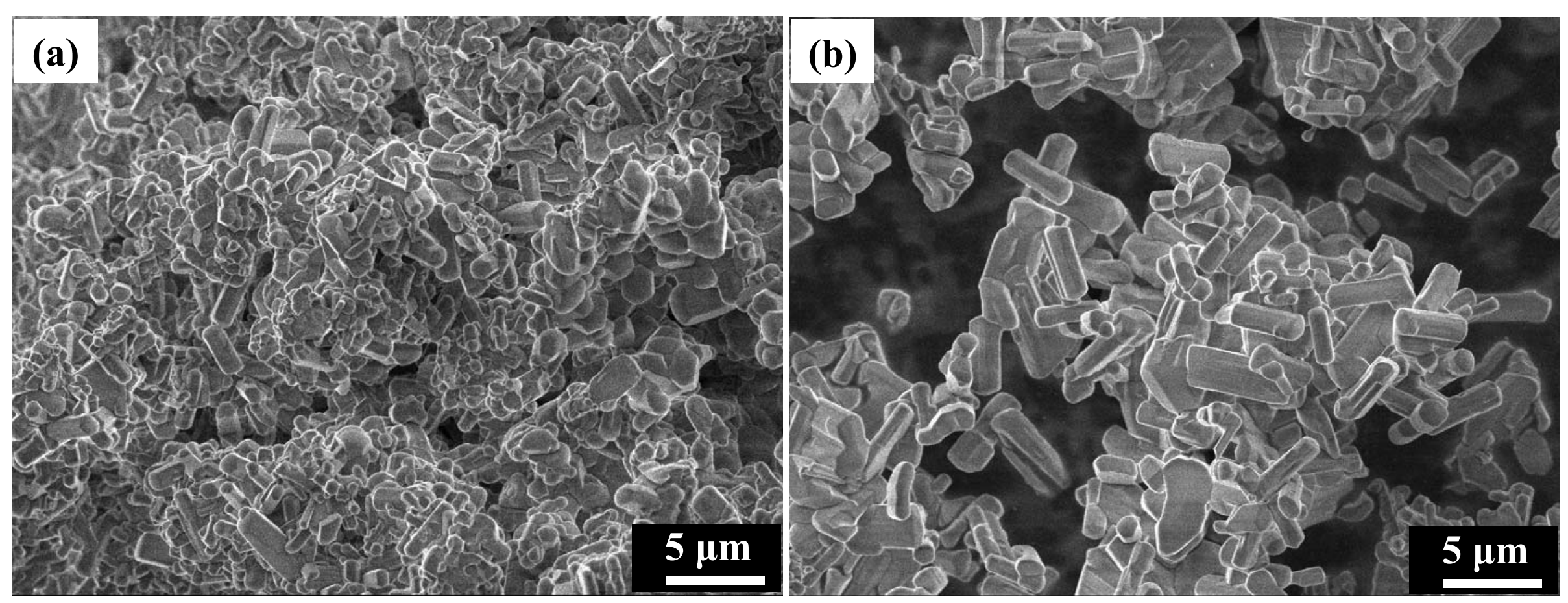

Fig. 12 